\title{
APRENDER COM CRIATIVIDADE: ADAPTAÇÃO DE MAPAS CONCEITUAIS PARA APRENDIZAGEM SIGNIFICATIVA NA GRADUAÇÃO
}

\section{CREATIVE LEARNING: ADAPTATION OF CONCEPTUAL MAPS FOR MEANINGFUL LEARNING IN A GRADUATION COURSE}

Suéllen Mota Marques Costaํㅜ, Rosângela Míriam Lemos Oliveira Mendonça², Viviane Gomes Marçal ${ }^{3}$, Patrícia Santos Delgado ${ }^{4}$

Submetido em: $28 / 04 / 2020$

Avaliado em: 28/09/2020

Aprovado em: 23/02/2021

\section{RESUMO}

A implementação contínua de melhorias no processo de ensino-aprendizagem é uma meta para todos os profissionais comprometidos com a educação. Na busca por tais objetivos, diversos métodos são estudados, no intuito de encontrar opções adequadas para cada contexto, como por exemplo, o nível (fundamental, médio, graduação, etc.) e o tipo de curso. Nesse sentido, este trabalho relata uma experiência de adaptação de um método de aprendizagem significativa, os mapas conceituais, para melhoria da aprendizagem de estudantes de graduação em Design de Ambientes da Escola de Design da Universidade do Estado de Minas Gerais (ED-UEMG). Participaram do projeto 29 estudantes do penúltimo período do curso, sendo conforto ambiental o tema para elaboração dos mapas. 0 objetivo foi compreender se a flexibilização proposta para o método seria compatível com estudantes de um curso com expressivo viés criativo. Dentre as modificações permitidas pode-se citar o uso de cores, desenhos à mão livre e colagens. O método de pesquisa consistiu em explicação da proposta aos estudantes; aulas expositivas sobre o tema; elaboração de exercícios de fixação; produção dos mapas (parciais e sintético) individuais; pesquisa de opinião com os envolvidos para avaliação da eficácia do método proposto; tratamento e análise dos dados, geração de resultados e discussão dos mesmos. Dessa experiência resultaram mapas diversificados, criativos e ímpares, bem como o procedimento foi bem avaliado pelos estudantes. Portanto, esse trabalho sinaliza que a aplicação do método proposto pode contribuir para a melhoria da aprendizagem de graduandos do curso de Design de Ambientes.

\footnotetext{
${ }^{1}$ Mestre em Construção Civil e especialista em Construção Civil pela Escola de Engenharia da UFMG, arquiteta e urbanista pela Escola de Arquitetura da UFMG, técnica em edificações pelo CEFET-MG. Atualmente é professora na Escola de Design da Universidade do Estado de Minas Gerais (ED-UEMG) e pesquisadora no Centro de Estudos em Design e Tecnologia (CEDTec). Correio eletrônico: suellenmc@hotmail. com

${ }^{2}$ Doutorado em Sistemas de Produção e Design Industrial (Itália-2014), com trabalho embasado na metodologia do Design Sistêmico, e pósdoutorado em sustentabilidade e abordagens sistêmicas (UFMG - 2018). Mestrado em Ciência da Computação (UFMG-1997) e em CABD (Scotland -1990). Graduação em Arquitetura e Urbanismo (UFMG-1986) e em Música (FUMA-1985). Atua como professora e pesquisadora (ED-UEMG) nos Centros de Design de Ambientes e Design de Moda, tratando especialmente os temas ergonomia, Design Sistêmico, Empreendedorismo e Sustentabilidade; consultora, avaliadora e auditora da qualidade de software no modelo MPS.Br; gerente de projetos (FUMSOFT); diretora de projetos em arquitetura e cultura (ArquiCAD).

${ }^{3}$ Doutora em Engenharia Civil pela Universidade Federal de Ouro Preto/UFOP (2016). Mestre em Engenharia Civil pelo Centro Federal de Educação Tecnológica de Minas Gerais/CEFET-MG (2010). Especialista em Educação a Distância pela Universidade Estadual de Montes Claros, UNIMONTES (2013). Especialista em História da Cultura e da Arte pela Universidade Federal de Minas Gerais/UFMG (2006). Graduada em Design de Ambientes (Decoração) pela Universidade do Estado de Minas Gerais/UEMG (2005). Correio eletrônico: gomesvivi@gmail.com ${ }^{4}$ Doutora em Sistema de Produção e Design Industrial. Correio eletrônico: pdelgadodesign@gmail.com
} 
PALAVRAS-CHAVE: Mapas Conceituais. Aprendizagem Significativa. Metodologias Ativas no Ensino Superior. Design de Ambientes.

\section{ABSTRACT}

The continuous implementation of improvements in the teaching-learning process is a goal for all professionals committed to education. In the search for such objectives, several methods are studied in order to find suitable options for each context, which can include the level (elementary, middle, and undergraduate schools, etc.) and the type of course. In this sense, this paper reports an experience of adapting a meaningful learning method, the concept maps, to improve the learning process of undergraduate students of Environment Design at the School of Design of the Minas Gerais State University (ED-UEMG). Twenty-two students from the penultimate period of the course participated in the project, with environmental comfort being the theme for the elaboration of the maps. The objective was to understand if the proposed flexibility for the method would be compatible with students of a course with significant creative bias. Permitted modifications include the use of colors, freehand drawings, and collages. The research method consisted of explaining the proposal to the students; lectures on the subject; preparation of fixation exercises; production of individual (partial and synthetic) maps; opinion poll with the participants to evaluate the effectiveness of the proposed method; data processing and analysis; generation and discussion of results. This experience resulted in diverse, creative and unique maps, and the procedure was well evaluated by the students. Therefore, this work indicates that the application of the proposed method may contribute to the improvement of the learning among the undergraduates of the Environment Design course.

KEYWORDS: Conceptual Maps. Meaningful Learning. Active Methodologies in University Graduate. Design of Environments. 


\section{INTRODUÇÃO}

O processo ensino-aprendizagem e suas consequências na construção do conhecimento são temas importantes discutidos pela comunidade científica. Dentre eles, destacam-se os trabalhos do psicólogo David P. Ausubel. Segundo Ausubel (2003), o conceito de aprendizagem por recepção significativa consiste na obtenção de novos conhecimentos a partir de material de aprendizagem oferecido por métodos específicos. Contudo, para que a aprendizagem significativa seja eficaz, o estudante deve ter disposição para aprender, bem como o conteúdo escolar precisa ter significado para o estudante, com ênfase na sua experiência (PELIZZARI et al.,2002).

Ausubel propõe que os indivíduos apresentam uma organização cognitiva interna baseada em conhecimentos de caráter conceitual. A complexidade de tal ordenação depende mais das relações dos conceitos entre si do que do número de conceitos presentes. Portanto, a estrutura cognitiva é compreendida, fundamentalmente, como uma rede de conceitos organizados de modo hierárquico de acordo com graus de abstração e de generalização. Conforme a teoria de Ausubel, para alcançar a aprendizagem significativa é necessário compreender o processo de modificação do conhecimento, e reconhecer a importância dos processos mentais nesse sentido (PELIZZARI et al., 2002).

Novak e sua equipe desenvolveram uma pesquisa baseada na psicologia da aprendizagem de Ausubel, a qual almejava entender as mudanças na compreensão da ciência por crianças. Ao longo desse estudo, os pesquisadores entrevistaram um grande número de indivíduos e tiveram dificuldade na identificação de alterações apenas examinando entrevistas transcritas. Como resultado desses estudos, surgiram os mapas conceituais (NOVAK e CAÑAS, 2010).

Em consonância com os estudos de Ausubel (2000), Novak e Cañas (2010) reforçam a existência da atividade cerebral no intuito de organizar hierarquicamente o conhecimento e sinalizam que métodos de ensino facilitadores desse processo aumentariam significativamente a capacidade de aprendizado de qualquer estudante. Nesse sentido, os autores expõem os mapas conceituais, os quais podem ser definidos como ferramentas gráficas para organização e representação do conhecimento (Figura 1).
Eles [os mapas conceituais] incluem conceitos, geralmente dentro de círculos ou quadros de alguma espécie, e relações entre conceitos, que são indicadas por linhas que os interligam. As palavras sobre essas linhas, que são palavras ou frases de ligação, especificam os relacionamentos entre dois conceitos (NOVAK e CAÑAS, 2010, p. 10).

Figura 1 - Exemplo de mapa conceitual. Concept map example.

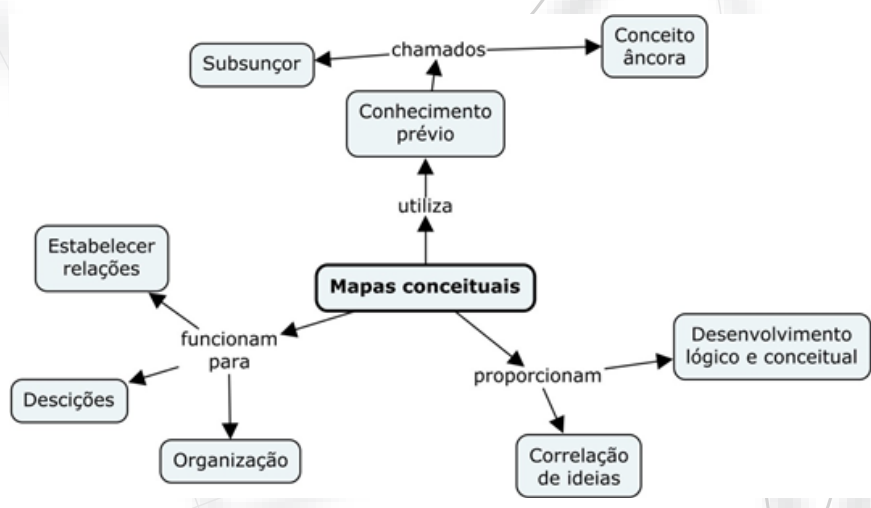

Fonte: DRINKO, PINTO e CASTRO, 2016, s/p.

A seu turno, Mendes et al. (2017, p. 184) relatam que a teoria da aprendizagem significativa promove "a construção do novo conhecimento a partir de conhecimentos já estabelecidos na estrutura cognitiva do aprendiz".

Logo, pode-se concluir que métodos coerentes com a aprendizagem significativa devem estimular a organização hierárquica dos conceitos e, concomitantemente, estimular relações entre o conhecimento prévio e o conhecimento novo, com geração de significados para o aprendiz. Nesse sentido, os mapas conceituais, conforme proposto por Novak e Cañas (2010) apresentam-se como importante ferramenta para o alcance de tais objetivos. No entanto, a estrutura dos conceitos e os significados gerados são particulares de cada estudante, consequentemente, os mapas conceituais são estruturas gráficas únicas. Ao considerar tal particularidade, surge o questionamento se os mapas conceituais poderiam também ser uma ferramenta de expressão artística dos sujeitos, ultrapassando os limites propostos por Novak e Cañas (2010) (Figura 1) ao incorporar elementos como cores e desenhos. Ademais, convém 
refletir se tais recursos gráficos poderiam contribuir para a otimização da aprendizagem, uma vez que tais mapas conceituais adaptados poderiam fortalecer as relações de significado entre autor e obra, ou seja, entre o estudante e o mapa produzido por ele.

\section{O USO DOS MAPAS CONCEITUAIS NO ENSINO SUPERIOR}

Segundo Masetto (2003), tradicionalmente, o foco da educação de nível superior reside no ensino. Esse paradigma da educação convencional apoia-se em três pilares principais, a saber: organização curricular centrada em disciplinas conteudísticas e técnicas; corpo docente com Mestrado e Doutorado em sua área de conhecimento (mas nem sempre com competência na área pedagógica) e uma metodologia que se esgota em noventa por cento das atividades no formato de aulas expositivas.

Neste paradigma, o sujeito do processo é o professor, uma vez que ele ocupa o centro das atividades e das diferentes ações: é ele quem transmite, quem comunica, quem orienta, quem instrui, quem mostra, quem dá a última palavra, quem avalia, quem dá a nota. Sua grande e constante pergunta é: o que devo ensinar aos meus alunos? $\mathrm{E}$ o aluno como aparece? Como o elemento que segue, receptor, assimilador, repetidor. Ele só reage em resposta a alguma ordem ou pergunta do professor (MASETTO, 2003, p. 2)

Todavia, o autor propõe um novo paradigma para a educação de nível superior, com ênfase na aprendizagem, isto é, no desenvolvimento das habilidades intelectuais, humanas e profissionais dos estudantes, bem como de suas atitudes e valores (MASETTO, 2003).

A ênfase na aprendizagem como paradigma para o Ensino Superior alterará o papel dos participantes do processo: ao aprendiz cabe o papel central, de sujeito que exerce as ações necessárias para que aconteça sua aprendizagem: buscar as informações, trabalhá-las, produzir um conhecimento, adquirir habilidades, mudar atitudes e adquirir valores. (...) O professor terá substituído seu papel exclusivo de transmissor de informações para o de mediador pedagógico ou de orientador do processo de aprendizagem de seu aluno. Donde sua pergunta agora será: o que meu aluno precisa aprender de todo o conhecimento que tenho e de toda a experiência que tenho vivido para que ele possa desenvolver sua formação profissional? O ângulo é outro. A variação foi de 180 graus. (MASETTO, 2003, p.3)

Evidentemente, o novo paradigma da educação superior, pressupõe o uso de novas abordagens em sala de aula. Nesse sentido, Masetto (2003), propõe novas estratégias no intuito de promover a aprendizagem, sem, contudo, extinguir as aulas expositivas, as quais podem ser conjugadas com os novos procedimentos.

Schimidt et al. (2014) aplicaram um método de ensino diferente do convencional, os mapas conceituais, em uma disciplina do curso de graduação em Odontologia, com o envolvimento de 44 estudantes. A primeira etapa da experiência contou com uma aula teórica sobre mapas conceituais, com ênfase na integração de conceitos. Contudo, antes de iniciarem a construção do mapa, os aprendizes preencheram questionário a respeito do tema escolhido. Além disso, após a elaboração do mapa, os estudantes preencheram o mesmo questionário, para fim de comparação das respostas pelos professores.

Como resultado, Schimidt et al. (2014), notaram um aumento no número de acertos no segundo questionário em relação ao primeiro. Portanto, os autores concluíram que os mapas conceituais proporcionaram um aperfeiçoamento significativo no aprendizado e um estímulo ao interesse dos graduandos pela disciplina.

Por sua vez, Silva, Lima e Santos (2017), relatam uma experiência do uso de mapas conceituais em uma disciplina de um curso de graduação da área da saúde, com o envolvimento de 30 graduandos e uma monitora, estudante de pós-graduação. Inicialmente, o projeto preparou os educandos e a monitora, por meio de quatro etapas.

A primeira etapa consistiu em contextualização teórica, com vistas a conscientizar os envolvidos para a importância e utilidade dos mapas conceituais. Por sua vez, na segunda etapa, foram apresentados aos estudantes exemplos de mapas desenvolvidos por outros 
grupos discentes, com o intuito de ilustrar a prática e promover um melhor entendimento do procedimento. Em seguida, procedeu-se à construção coletiva de um mapa conceitual manuscrito (terceira etapa). Por fim, a quarta etapa destinou-se à ampliação da concepção teórica ao disponibilizar artigos para análise e apresentar softwares disponíveis gratuitamente para confecção dos mapas. Em seguida, os estudantes produziram mapas conceituais em grupo, sendo que cada equipe abordou parte de um mesmo artigo. Ao final, ocorreu a apresentação dos mapas para a turma, com consequente discussão da experiência (SILVA, LIMA E SANTOS, 2017).

Como resultados, Silva, Lima e Santos (2017) apresentaram os depoimentos dos discentes, os quais relataram que o procedimento facilitou a compreensão do tema proposto, bem como apontaram que os mapas conceituais poderiam ser úteis inclusive em outras disciplinas.

Logo, tanto o trabalho de Schimidt et al. (2014) quanto o relato de experiência de Silva, Lima e Santos (2017) sinalizam as possibilidades de melhoria da aprendizagem dos graduandos com o uso de mapas conceituais. Contudo, tais estudos foram aplicados em cursos da área da saúde. Cabe, portanto, o questionamento se tal método impactaria positivamente a aprendizagem quando aplicado ao curso de Design de Ambientes.

\section{MAPAS CONCEITUAIS PARA DESIGN DE AMBIEN- TES: UMA CONVERGÊNCIA POSSÍVEL?}

Abreu (2015) relata que o design abrange tanto o campo da objetividade, quanto o campo dos valores subjetivos, sendo o usuário um dos elementos fundamentais do projeto de um designer de ambientes. Logo, questões do âmbito funcional, estético e simbólico das suas esferas social, econômica e cultural não devem ser esquecidas, uma vez que, o profissional tem por premissa a elaboração de espaços confortáveis e eficientes para aquele que for usufruir. Esta é uma área de conhecimento que inclui ambientes residenciais, empresariais, institucionais, industriais ou efêmeros, arquitetônicos ou não arquitetônicos, virtuais e de transporte (ABREU,2015).

Corroborando os estudos de Abreu (2015), a lei federal número 13369 publicada em 2016 reconheceu a profissão de designer de interiores e ambientes, bem como estabeleceu diversas competências para esses profissionais (BRASIL, 2016).

Designer de interiores e ambientes é o profissional que planeja e projeta espaços internos, visando ao conforto, à estética, à saúde e à segurança dos usuários, respeitadas as atribuições privativas de outras profissões regulamentadas em lei (BRASIL, 2016, s/p).

[...]

Art. $4^{\circ}$ Compete ao designer de interiores e ambientes:

I - estudar, planejar e projetar ambientes internos existentes ou pré-configurados conforme os objetivos e as necessidades do cliente ou usuário, planejando e projetando o uso e a ocupação dos espaços de modo a otimizar o conforto, a estética, a saúde e a segurança de acordo com as normas técnicas de acessibilidade, de ergonomia e de conforto luminoso, térmico e acústico devidamente homologadas pelos órgãos competentes;

[...]

VI - criar, desenhar e detalhar móveis e outros elementos de decoração e ambientação; (BRASIL, 2016, s/p.)

Nota-se, portanto, que o trabalho do design de ambientes envolve diversos processos de criação, com vistas à elaboração de projetos que atendam às necessidades específicas de cada usuário. Por focar nas demandas singulares de cada cliente, o designer de ambientes necessita de certa flexibilidade metodológica e criativa, de modo a adequar-se a diferentes situações, sem perder de vista a satisfação de seu contratante. Consequentemente, os cursos de graduação em Design de Ambientes devem optar por métodos de ensino-aprendizagem em consonância com tal flexibilidade, no intuito formar profissionais qualificados.

Por outro lado, a análise da definição de Abreu (2015) sugere que o design de ambientes envolve processos complexos e interconectados. Nesse sentido, os mapas conceituais poderiam facilitar o entendimento dos sistemas, uma vez que possibilita a criação de uma estrutura lógica para processos complexos. Nesse sentido, os mapas conceituais teriam muito a contribuir para a estruturação das ideias dos estudantes, tornando mais claro, tanto as variáveis dos processos, quanto as 
relações entre elas. Consequentemente, a clara compreensão dos sistemas poderia contribuir para decisões mais conscientes e com melhor controle dos resultados.

\section{MAPAS CONCEITUAIS ADAPTADOS PARA GRADU- AÇÃO EM DESIGN DE AMBIENTES}

Os mapas conceituais adaptados foram desenvolvidos e avaliados por estudantes do penúltimo período do curso de Design de Ambientes da Escola de Design da Universidade do Estado de Minas Gerais (ED-UEMG). Participaram do projeto 29 estudantes na faixa etária de vinte a trinta anos, sendo a maioria do sexo feminino. A experiência foi composta por cinco encontros presenciais.

Os mapas deveriam abordar os conceitos fundamentais do conforto ambiental, o qual, segundo Lamberts et al. (2014), consiste em um conjunto de condições ambientais que possibilitam às pessoas sensações de bem-estar térmico, acústico, visual e antropométrico, sem prescindir do conforto olfativo e da qualidade do ar. Convém notar que o conforto ambiental é de tema de grande importância para a atuação profissional do designer de ambientes. Por ter como elemento principal o usuário, os projetos dos ambientes devem visar a garantia da qualidade de vida das pessoas. Promover a referida qualidade de vida requer projetos que estabeleçam espaços com temperatura agradável, distribuição do som e controle de ruído compatíveis com as tarefas a serem desempenhadas, bem como prover sistemas de iluminação capazes de gerar nos usuários a sensação de bem-estar.

Portanto, uma vez que cabe ao designer de ambientes especificar cores, revestimentos e acabamentos, tal escolha interfere no conforto térmico dos ambientes internos. No que concerne ao layout, o trabalho do designer de ambientes pode interferir na circulação do ar nos espaços internos de uma edificação, uma vez que o mobiliário pode servir de barreira ou de elemento direcionador do fluxo de ar (SANTANA et al., 2019, s/p).

No intuito de projetar ambientes capazes de garantir o conforto ambiental, deve-se, primeiramente, conhecer o clima no qual a edificação está inserida. $O$ estudo do clima pode ser feito por meio das variáveis climáticas, isto é, temperatura, radiação solar, luz natural, vento e umidade. Por outro lado, um bom projeto também deve avaliar características inerentes aos usuários, como metabolismo e vestimenta (LAMBERTS et al., 2014). Portanto, esperava-se os mapas conceituais auxiliassem os estudantes tanto na compreensão da importância do conforto ambiental, quanto no entendimento e assimilação dos conceitos fundamentais do tema.

No primeiro encontro, explicou-se o método dos mapas conceituais aos universitários, de modo que eles tomassem consciência de seu papel ativo na apropriação do conhecimento. Nesse momento, foi informado aos educandos sobre a possibilidade de realizar também croquis, ou seja, desenhos à mão livre, bem como outras técnicas de tratamento gráfico (como colagens, por exemplo) na elaboração dos mapas conceituais, embora não sejam recursos próprios do método. Em seguida, os estudantes tiveram contato com o tema por meio de aula expositiva, seguida de exercícios de fixação. Por fim, cada aprendiz produziu um mapa conceitual daquele encontro. Tal opção está em consonância com o trabalho de Masetto (2003), no qual recomenda-se que as aulas expositivas sejam integradas aos novos métodos de aprendizagem.

O procedimento de aula expositiva, seguida por exercício de fixação e elaboração do mapa conceitual repetiu-se na segunda, terceira e na quarta reunião. No quinto encontro, cada graduando produziu um mapa síntese dos anteriores e preencheram questionário para avaliação da experiência. A elaboração dos mapas sintéticos teve duplo objetivo. Em primeiro lugar, buscou-se estimular o aprendiz a refletir sobre as alterações necessárias na estrutura hierárquica dos conceitos dos encontros anteriores (expresso no mapa do referido encontro), em função dos conhecimentos adquiridos nas reuniões posteriores. Em segundo lugar, no mapa síntese o aprendiz deveria buscar relacionar os conceitos dos encontros entre si. O resultado foi um mapa único, específico para cada estudante, que representa o modo como o indivíduo organiza, relaciona e representa os conceitos apreendidos.

Com o intuito de estimular a autoconsciência sobre o processo de aprendizagem, os estudantes foram questionados sobre as contribuições da experiência para sua aprendizagem em particular, sendo aplicado questionário curto (quatro perguntas), anônimo e em papel. Foram 
três perguntas de múltipla escolha, sendo apenas duas as opções de respostas, dicotômicas (sim ou não). Havia também uma questão na qual o universitário deveria estabelecer uma nota para a sua aprendizagem promovida pelo método empregado.

\section{AVALIAÇÃO DOS MAPAS CONCEITUAIS ADAPTA- DOS}

Os mapas conceituais sintéticos produzidos pelos estudantes foram diversificados. Embora apresentassem elementos do modelo sugerido por Novak e Cañas (2010), como quadros e setas (Figura 1), também constam elementos peculiares, os quais podem ser associados ao processo cognitivo específico de cada estudante (Figuras 2 a 5).

Figura 2 - Mapa conceitual com variação do tamanho e da espessura das letras. Varying size and letters thickness in concept map.

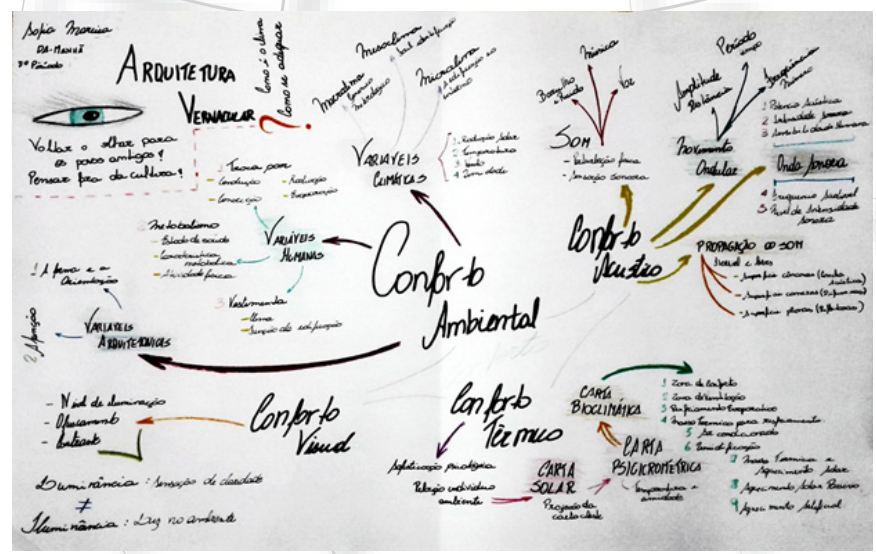

Fonte: Arquivo das autoras.

No mapa conceitual da Figura 2, nota-se que a hierarquização dos conceitos ocorre principalmente pelo tamanho e espessura das letras. Ou seja, os conceitos mais abrangentes apresentam letras maiores e mais espessas, enquanto os textos menores e mais finos representam conceitos mais específicos. Além disso, o conceito gerador situa-se estrategicamente no centro da folha.
Figura 3 - Mapa conceitual em colunas, com uso de croquis. Columns and sketches in conceptual maps.

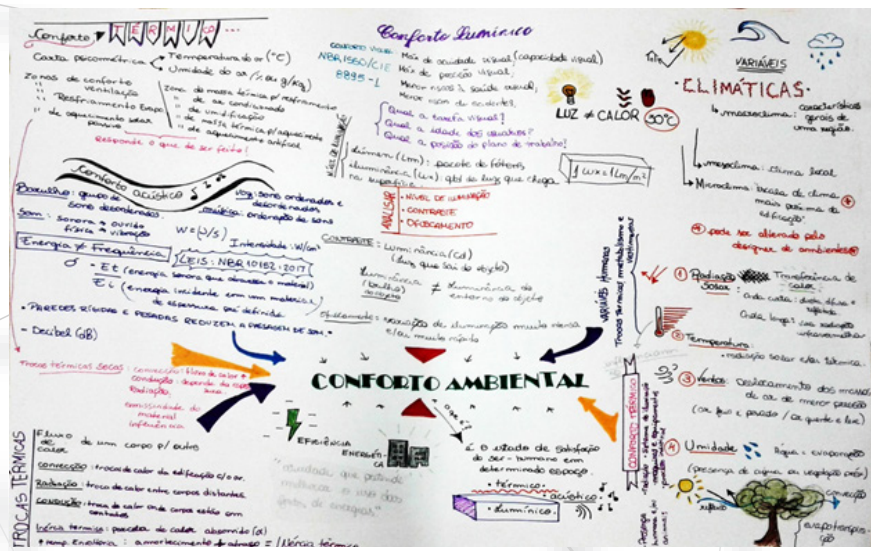

Fonte: Arquivo das autoras.

Por sua vez, o mapa da Figura 3 também apresenta alguns elementos do mapa conceitual proposto por Novak e Cañas (2010) (Figura 1) como as palavras e as setas. Contudo, também possui desenhos à mão livre e a classificação da informação é feita por meio de colunas. Porém, as três colunas convergem, por meio de setas, para o conceito mais abrangente e gerador, disposto estrategicamente no centro da folha. Por sua vez, os desenhos sintetizam conceitos e relações de significados, chamam mais a atenção do que as palavras e tornam o mapa heterogêneo e peculiar.

Figura 4 - Mapa conceitual com colagem de papeis coloridos. Collage of colored papers in concept map.

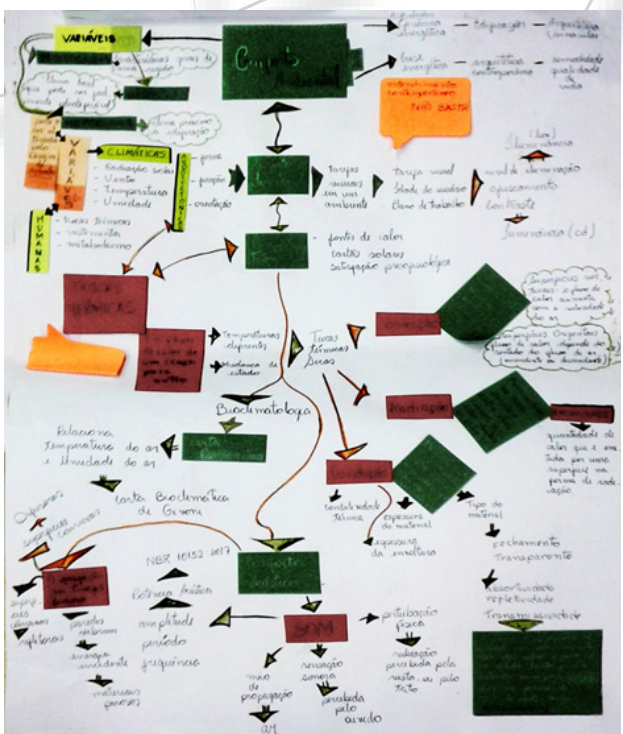

Fonte: Arquivo das autoras. 
A Figura 4 consiste em um mapa conceitual produzido com colagem de papeis coloridos, os quais assemelham-se aos retângulos da Figura 1. Embora o contraste inadequado entre texto e fundo tenha prejudicado a legibilidade em alguns trechos, é notável o uso da cor de fundo dos retângulos como elemento estruturador. A partir do conceito gerador, posicionado no topo e no centro da folha, derivam os conceitos secundários seguindo um eixo principal descendente. As cores dos quadros estabelecem diferenças e semelhanças entre os conceitos, assim como as setas. O uso de balões de cor mais clara para marcar observações importantes também é uma particularidade desse mapa.

Figura 5 - Mapa conceitual com hierarquização dos conceitos por tamanho de círculo. Circle scale for hierarchize concepts in conceptual maps.

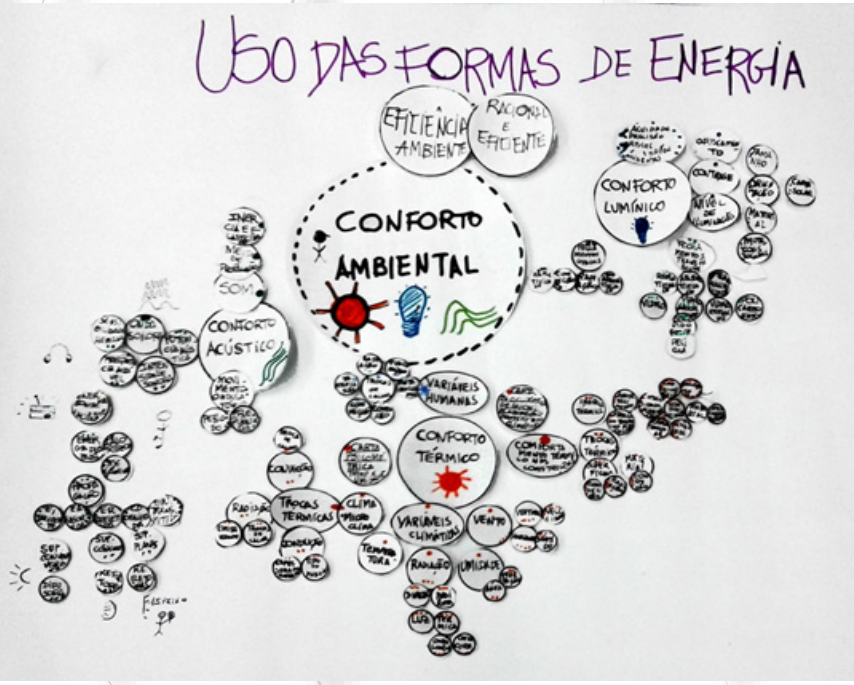

Fonte: Arquivo das autoras.

A seu turno, o mapa da Figura 5 apresenta uma hierarquização de conceitos sem o uso de setas. No caso, a classificação é estabelecida pelo tamanho da forma que envolve a palavra. Portanto, o conceito mais geral apresenta o maior círculo, envolto por uma linha tracejada. Os conceitos mais específicos, que derivam do conceito fundamental, são envoltos por círculos cada vez menores, à medida que aumenta a especificidade. Além disso, a posição dos círculos entre si também consiste em indicador das relações entre os termos.

Após a aplicação dos questionários, os dados foram tratados, sendo geradas as Figuras 6 a 9, sendo que cada figura corresponde a uma pergunta do formu- lário.

Figura 6 - Avaliação feita pelos estudantes por meio da comparação do método proposto com aulas exclusivamente expositivas. Assessment of involved students by comparing proposed method with lectures.

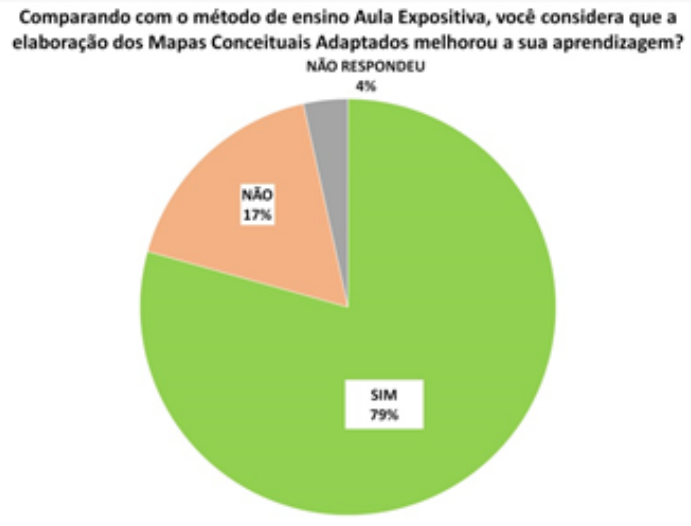

Fonte: Arquivo das autoras.

Conforme mostra a Figura 6, em comparação com o método da aula exclusivamente expositiva, $79 \%$ dos estudantes responderam que os mapas conceituais adaptados melhoraram sua aprendizagem. Contudo, convém lembrar que os mapas conceituais foram aplicados de modo integrado com exposição do conteúdo e exercícios de fixação. Logo, a comparação foi feita entre o método dos mapas conceituais adaptados (da maneira descrita neste trabalho) com aulas exclusivamente expositivas.

Figura 7 - Avaliação dos estudantes envolvidos quanto à liberação para uso de desenhos à mão livre nos mapas conceituais. Assessment of involved students about the permission of freehand drawings in the concept maps.

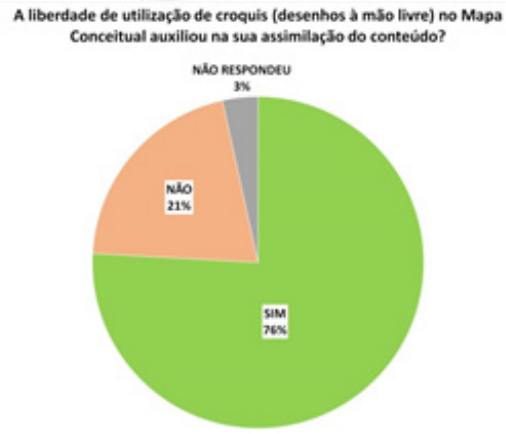

Fonte: Arquivo das autoras. 
No que concerne à utilização de croquis (desenhos à mão livre) nos mapas conceituais, $76 \%$ dos universitários responderam que tal permissão auxiliou na assimilação do conteúdo (Figura 7). Ademais, $79 \%$ dos universitários respondeu que utilizaria o método dos mapas conceituais adaptados para aprendizado de outros assuntos (Figura 8). Portanto, é provável que a maioria dos estudantes incorpore o método como um recurso ativo de apropriação do conhecimento.

Figura 8 - Intenção de uso do método dos mapas conceituais adaptados para aprendizagem de outros temas. Intention to use the adapted concept maps method for learning other subjects.

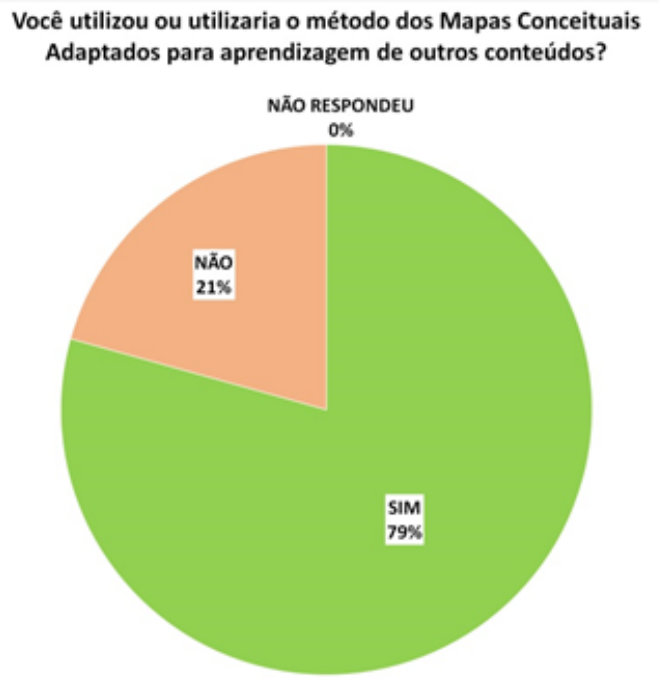

Fonte: Arquivo das autoras.

Houve também uma questão que indagou sobre qual nota os estudantes dariam para a importância do uso dos mapas conceituais adaptados (Figura 9). Para tanto, considerou-se uma escala de zero a dez, na qual zero seria nenhuma importância e dez, importância máxima. Conforme mostra a Figura 9, apenas 6 dos 29 universitários atribuiu nota menor ou igual a 5 para a importância do método, isto é, $20 \%$ dos entrevistados considera o método pouco relevante para a aprendizagem. Por outro lado, 23 dos 29 entrevistados conferiu nota superior a 5 , logo $80 \%$ dos graduandos considerou o método relevante. A nota 9 foi a que apresentou o maior número de respostas, correspondendo a $24 \%$ dos entrevistados. Ao agrupar as notas 8,9 e 10, ou seja, os pontos mais altos da escala, pode-se dizer que
$55 \%$ dos graduandos avaliou o método dos mapas conceituais adaptados como muito relevantes para a sua aprendizagem.

Figura 9 - Notas atribuídas pelos entrevistados para a importância do método dos mapas conceituais adaptados para a sua aprendizagem. Scores by students for the relevance of the adapted concept map method for their learning.

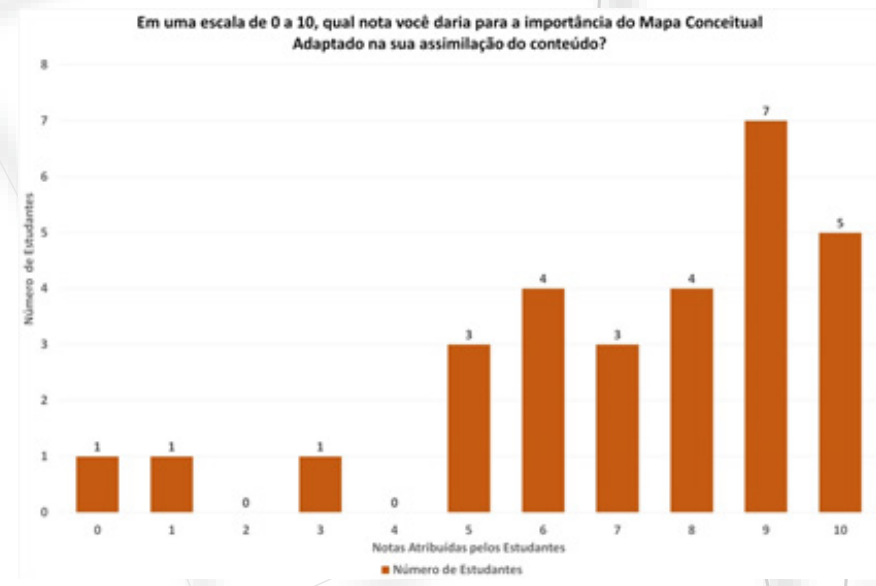

Fonte: Arquivo das autoras.

Com base nas análises feitas, pode-se concluir que as alterações feitas no método dos mapas conceituais resultaram em mapas únicos e criativos, em consonância com as características do curso de graduação em Design de Ambientes. Ademais, as respostas dos estudantes envolvidos indicam um horizonte positivo para a aplicação do método, uma vez que a maioria deles indicou que os mapas conceituais adaptados contribuíram para a melhoria do aprendizado.

\section{CONSIDERAÇÕES FINAIS}

Como base nas respostas dos estudantes envolvidos, nota-se que, para a maioria deles, o método dos mapas conceituais adaptados contribuiu de modo significativo para a otimização da aprendizagem. Convém notar que a autorização para uso de desenhos à mão livre, colagens etc. também foi considerada positiva por grande parte dos graduandos.

Conforme citado anteriormente por Pelizari, et al. (2002), a aprendizagem significativa requer relevância e significado do conteúdo escolar para o aprendiz, com ênfase na experiência deste. Logo, com base nos resul- 
tados dessa experiência, conclui-se que a flexibilização do método proposto por Novak e Cañas (2010) contribuiu para o aprendizado, uma vez que permitiu a cada estudante representar e estruturar os conceitos com base em seu processo cognitivo peculiar. Em outras palavras, embora houvesse um método orientador, nesse caso, atribuir ao estudante certo grau de autonomia corroborou para a eficiência do processo. Ademais, a construção da autonomia do estudante é um dos pilares do novo paradigma da educação superior proposto por Masetto (2003).

Portanto, os mapas conceituais adaptados da maneira proposta neste trabalho mostraram-se um recurso de aprendizagem que contribui para o desenvolvimento da autonomia dos estudantes, bem como pode melhorar a assimilação do conteúdo em um curso de graduação em Design de Ambientes. Porém, como diretrizes para trabalhos futuros, pode-se citar a necessidade de testar o método em outros grupos de estudantes, preferencialmente em outras universidades e em outras regiões do país, de modo a avaliar a eficácia do método em outros contextos.

\section{REFERÊNCIAS}

ABREU, S. M. B. M. Aspectos subjetivos relacionados ao Design de Ambientes: um desafio no processo projetual, 2015. Dissertação (Mestrado em Design) - Escola de Design da Universidade do Estado de Minas Gerais, Belo Horizonte, 2015. Disponível em: http://anapaulanasta.com/wpcontent/ uploads/2015/09/DISSERTA\%C3\%87\%C3\%83O-SIMONE-M.B.MARQUES-DEABREU.pdf . Acesso em: 22 maio 2019.

AUSUBEL. D. P. Aquisição e retenção de conhecimentos: uma perspectiva cognitiva. Lisboa: Plátano Edições Técnicas, 2000.

BRASIL. Lei Federal 13369. Dispõe sobre a garantia do exercício da profissão de designer de interiores e ambientes e dá outras providências. Brasília, DF: Presidência da República, [2016]. Disponível em: http://www.planalto.gov.br/ccivil_03/_ato2015-2018/2016/lei/L13369. htm . Acesso em: 18 jan. 2019.

DRINKO, A.; PINTO, S. E. de S. Mapas Conceituais na
Física Quântica e Clássica. In: SIMPÓSIO NACIONAL DE ENSINO DE CIÊNCIA E TECNOLOGIA, 5, 2016, Ponta Grossa. Anais [...]. Ponta Grossa: Programa de Pós-Graduação em Ensino de Ciência e Tecnologia, 2016. Disponível em: http://www.sinect.com.br/2016/selecionados.php?ordem01=autor\&ordem02=autor. Acesso em: 28 mar. 2020.

LAMBERTS, R.; DUTRA, L.; PEREIRA, F.O.R. Eficiência energética na arquitetura. 3. ed. São Paulo: ProLivros, 2014. Disponível em: http://www.labeee.ufsc.br/ publicacoes/livros . Acesso em: 15 jan. 2018.

MASETTO, M. T. Docência universitária: repensando a aula. In: TEODORO, A.; VASCONSCELOS, M.L. (org.) Ensinar e aprender no ensino superior: por uma epistemologia pela curiosidade da formação universitária. Ed. Cortez: Mackenzie, 2003. p.1-17. Disponível em: https://ufsj.edu.br/portal2-repositorio/File/napecco/Abordagens/Masetto\%20-\%20Docencia\%20Universitaria. pdf . Acesso em: 25 nov. 2019.

MENDES, A. A.; VENTURA, R. C. M. O.; SOUZA, R. A.; MIRANDA, N. T. P.; ARAUJO, G. L.; ARAKAKI, F. S. F. A percepção dos estudantes do curso de Administração a respeito do processo de implantação de metodologias ativas de ensino-aprendizagem - o desenvolvimento da aprendizagem significativa. Pensar Acadêmico, v. 15, n. 2, p. 182-192, 2017. Disponível em: http://pensaracademico.facig.edu.br/index.php/pensaracademico/article/ view/356 . Acesso em: 5 out. 2018.

NOVAK, J. D.; CAÑAS. A. J. A Teoria Subjacente aos Mapas Conceituais e como Elaborá-los e Usá-los. Práxis Educativa, Ponta Grossa, v.5, n.1, p. 9-29, jan.-jun. 2010. Disponível em: http://www.revistas2.uepg.br/index.php/praxiseducativa/article/view/1298/944. Acesso em: 12 set. 2018. Tradução de The theoryunderlying concept maps and how to construct and use them. Disponível em: http://cmap.ihmc.us/Publications/ResearchPapers/TheoryUnderlyingConceptMaps.pdf . Traduzido com a autorização dos autores. Tradução de Luis Fernando Cerri (PPGE/UEPG), com revisão técnica de Fabiano Morais.

PELIZZARI, A.; KRIEGL, M. L.; BARON, M. P.; FINCK, N. T. L.; DOROCINSKI, S. I. Teoria da Aprendizagem 


\section{rejvista educação}

APRENDER COM CRIATIVIDADE: ADAPTAÇÃO DE MAPAS CONCEITUAIS PARA APRENDIZAGEM SIGNIFICATIVA NA GRADUAÇÃO Suéllen Mota Marques Costa, Rosângela Míriam Lemos Oliveira Mendonça, Viviane Gomes Marçal, Patrícia Santos Delgado

Significativa Segundo Ausubel. PEC, Curitiba, v.2, n.1, p.41-42, 2002. Disponível em: http://portaldoprofessor. mec.gov.br/storage/materiais/0000012381.pdf . Acesso em: 12 set. 2018.

SANTANA, F.L.; FONSECA, L.A.; COSTA, S. M. M.; SALES, R. B.C.; ENGLER, R. C. Conforto Térmico em Habitação de Interesse Social: um Olhar do Designer de Ambientes com Foco em Soluções de Baixo Custo. In: FÓRUM HABITAR 2019: HABITAÇÃO E DESENVOLVIMENTO SUSTENTÁVEL, 5., 2019, Belo Horizonte. Anais [...]. Belo Horizonte: IEDS, 2019. Disponível em: https://even3.blob.core.windows.net/ processos/3dce1e7b882a4660881d.pdf . Acesso em: 6 dez. 2019.

SCHIMIDT, D.B.; HEGGENDORNN, L.H.; PEREIRA, H.S.; VIEIRA, V.; AGUIAR-ALVES, F. Mapas Conceituais no Ensino de Bioquímica, uma Integração entre os Conceitos Científicos. Revista de Ensino de Bioquímica, v. 12, n. 2, out. 2014. Disponível em: http://bioquimica.org. $\mathrm{br} / \mathrm{revista/ojs/index.php/REB/article/view/315} \mathrm{.} \mathrm{Acesso}$ em: 15 abr. 2018.

SILVA, K.R.; LIMA, M.D.O.; SANTOS, L.F. Utilização de Mapas Conceituais como Estratégia de Inovação Metodológica: Relato de Experiência. Revista Docência Ensino Superior, Belo Horizonte, v.7, n.1, p. 11-26, jan.-jun. 2017. Disponível em: https://seer.ufmg.br/index. php/rdes/article/view/1509 . Acesso em: 20 ago. 2018. 